Running Head: PRESCHOOL QUALITY AND CHILD DEVELOPMENT

Preschool Quality and the Development of Children from Economically Disadvantaged Families in India

Date of Final Submission: January 12, 2010 
Abstract

Research Findings: The influence of preschool quality on the development of 67, 4-year-old children from poor and rural families in South India was examined. Children's developmental status was assessed using a modified version of the McCarthy Scales of Children's Abilities and through physician ratings. Preschool quality was assessed through repeated systematic observations and by the Tamil Nadu Early Childhood Environment Rating Scale. Results indicated that higher preschool quality was associated with better overall development. Three variables, Age, Preschool Quality and Sex significantly contributed to prediction of developmental functioning. Age accounted for 35\% of the variance while Preschool Quality and Sex contributed another $31 \%$ and $5 \%$ of the variance, respectively.

Practice and Policy: Findings from this small-scale study suggest that programs which would be deemed to be of poor quality using Western standards appear to have benefits for the development of children from disadvantaged families in India. However, consistent with findings from studies conducted in other parts of the world, children in these contexts who attend higher quality preschools have better developmental outcomes than comparable children who attend similar but lower quality programs.

Keywords: preschool quality, child development, India 
Preschool Quality and the Development of Children

from Economically Disadvantaged Families in India

Preschool services are particularly important in the developing world as they are a vehicle to promote children's rights to survival, development and early education. It has been estimated that over 200 million children around the world under five do not develop adequately because they live in poverty and have poor health services, nutrition and care. These children are at-risk for delayed development and for underachievement at school, and poor child development has costs in terms of both psychological well-being and economic development (GranthamMcGregor et al., 2007). However, integrated, intensive, long-lasting, high quality early childhood interventions are effective in promoting child development and avert the loss of young children's development potential (Engle et al., 2007).

The Integrated Child Development Service (ICDS) is a Head Start type of intervention designed to promote the early development of Indian children from economically disadvantaged families. While the US Head Start program serves over 900,000 children, the preschool program considered in this paper, currently serves over 70 million children under the age of six with over 30 million children ranging in age from three to six years benefiting from its preschool education component (Government of India, 2007). This paper describes a small-scale exploratory study conducted to assess the influence of the quality of preschool centers under the ICDS scheme in India on children's development. Why is such an evaluation important? First, early childhood programs are implemented in varying ecological contexts and by examining the relationship between preschool quality and child development in different societies, we can gain a better understanding of what works and why in diverse settings. Second, limited attention has been directed at understanding the role of contextual factors and role of the quality of the early 
childhood programs in contributing to their (lack of) success. Third, it has been estimated that India has 65 million disadvantaged children which is the largest number among developing countries. Systematically conducted empirical studies of the influence of preschool interventions on child development are sorely needed in developing countries. Results from even small-scale studies in contexts where few such studies have been conducted have the potential to provide valuable information to policy makers about the effectiveness of these interventions.

\section{Preschool Quality}

The professional literature has tended to measure the quality of preschool programs in terms of structural or process dimensions, or both (Lamb, 1998). Structural measures of programs include staff-child ratios, staff qualifications, teaching experience and stability, health and safety factors, and the physical setting. Process measures refer to the quality of interactions between staff and children. There is considerable agreement that the physical and psychological environment, curriculum, learning and teaching approaches, teacher-child interactions, program management and community integration should be considered in defining quality in early childhood programs in all contexts (Association for Childhood Education International, 2006; Rao, 2007). There is, however, less agreement on the group size or teacher-child ratio necessary for a program to be considered high quality in different contexts (Tobin, Wu, \& Davison, 1987). Montie, Xiang and Schweinhart (2006) found that a predominance of child-initiated activities, higher levels of teacher education, more educational materials and less time in whole group activities were associated with better developmental outcomes in 10 countries. However, there is a dearth of cross-national research which has identified the features of high quality care in different countries (Montie, Xiang, \& Schweinhart, 2006). Culture affects the way that we define high quality early education and care, and the assumption that a single model of high 
quality care exists has been questioned (Dahlberg, Moss \& Pence, 1999). Standards for quality developed in one country may not be relevant to another. Consequently researchers have advocated culturally relevant frameworks for the evaluation of quality (Dahlberg et al., 1999; Roer-Stirer, 1996; Sylva et al., 2006; Woodhead, 1999). Cultural beliefs about early education affect the form of preschool education. Hence, small group size, stringent teacher to child ratios and "developmentally appropriate" curriculum models are considered hallmarks of high preschool quality in only some societies (Prochner, 2002, Tobin, 2005). Tobin (2005) points out that teacher-child ratios in Japan and France would be considered to represent low quality early education by U.S. standards but children in these contexts appear to be developing appropriately. Preschool Quality and Child Development

Research in the developed world has clearly demonstrated that high quality care is associated with better developmental outcomes (Peisner et al., 2001; Vandell \& Wolfe, 2000) and the potential for harm from low quality child care is a concern (UNICEF, 2008). While the existence of adequate resources for learning, including having professionally qualified early childhood educators, is a prerequisite for high quality programs, many developing countries lack the resources to attain standards for quality set in the developed world. In fact, many programs in the developing world would be considered of extremely poor quality using the benchmarks of the developed world and western observers may argue that children are better off staying at home than attending these low quality programs. However, in these contexts, we should perhaps focus more on defining quality in terms of outcomes for children and on identifying features of early education programs positively related to those outcomes rather than deeming a program of unacceptable quality.

Over the past few decades, large scale studies in the developed world, including the US 
and the UK have examined the relationship between the quality of preschool programs and children's outcomes. The Cost, Quality and Outcomes (1995), the NICHD Early Childcare Research Network (ECCRN) (2005) and the Effective Provision of Pre-school Education (EPPE) (Sylva et al., 2006) studies have followed children longitudinally and assessed the quality, quantity and type of child care at regular intervals. In the US, the Cost, Quality and Outcomes study found that high preschool quality was related to children's language and mathematical competence in Grade 2. The NICHD ECCRN study has charted at regular intervals the development of over 1,300 children from 10 sites from birth. Multiple indices were used to assess the quality of care provided (NICHD ECCRN, 2005). Results indicated that high quality care was related to better cognitive outcomes, less impulsivity and better social competence at 4.5 years (p. 346). In the UK, the EPPE study assessed a nationally representative sample of over 3000 children at ages 3, 5 and 7. Results indicated that children who attended higher quality preschools as measured by the Early Childhood Environment Rating Scale - Extension (ECERS-E) (Sylva, Siraj-Blatchford \& Taggart, 2003) had better language, cognitive and social development than other children. Further, children who started preschool earlier, i.e., at 3 years had better cognitive and linguistic skills than those who started later on (Sylva et al., 2003, 2006).

There is a dearth of studies on the relationship between preschool quality and child development in the developing world. Myers (2006) has reviewed longitudinal studies on the effects of programs of early childhood care and education in the developing world and noted that few studies assess quality concurrently and longitudinally. In a longitudinal nationwide study of the range of early childhood care and education programs in Cambodia, Rao and Pearson (2007) found that children in the highest quality preschool had significantly better developmental functioning than children in all other programs and the control group. Results from longitudinal 
South Asian studies of children who have attended preschool programs in Bangladesh (Aboud, 2004; Moore, Akter \& Aboud, 2008), India (Zaveri, 1993) and Nepal (Save the Children, 2003) have also shown benefits to participating children in terms of school readiness, attendance and cognitive development compared to those who did not attend preschool programs. Aboud (2004) assessed the quality of preschool programs in Bangladesh, and found that even those which would be considered to be low to mediocre quality by western standards had significant positive effects on children's learning and achievement. Such findings further underscore the necessity of looking at quality in context (Myers, 2006) and for using situationally appropriate tools to evaluate preschools. In contexts where maternal literacy is very low and children are very socially disadvantaged, even the minimum input provided by programs which include food supplementation and some adult-centered preschool stimulation seem to make a positive difference to young children.

Only one published study conducted in India has examined the relationship between preschool program quality and child outcomes. These were assessed by contextually relevant measures developed for the study, i.e., the Tamil Nadu Early Childhood Environment Rating Scale (TECERS) (Isley, 2000), and the Child Learning Competency Test (CLeCT) (M.S. Swaminathan Research Foundation (MSSRF), 2000), respectively. Both these instruments were developed and validated on Indian children from disadvantaged backgrounds hence are suitable for the participants of the present study. The TECERS is an adaptation of the widely used Early Childhood Environment Rating Scale (Harms \& Clifford, 1980) and cognitive, language, perceptual motor and socio-emotional competencies were measured by the CLeCT. One hundred and ninety-three 4-year-olds, from 4 types of early childhood education centers (ICDS, Tamil Nadu Integrated Nutrition Program, Non Government Organization and Private) 
participated in the study. Children were from economically disadvantaged backgrounds and lived in urban and rural areas. Program quality was only assessed once. Results indicated that the quality of early childhood centers was significantly related to children's competency after controlling for fathers' education level and urban/rural residence.

Integrated Child Development Services (ICDS)

The ICDS scheme has been the Indian government's major early childhood intervention strategy and in 1995 the government made a commitment to universalize the ICDS for all eligible beneficiaries. This has led to a marked expansion of the program which serves over 70 million children under the age of six (Government of India, 2007). Under this nationwide program, children up to the age of six, and expectant and nursing mothers, benefit from a package of services that includes medical checks, immunizations, referral services, supplementary feeding, preschool education, and health and nutrition education. It should be noted that in India, children from the most economically disadvantaged backgrounds attend the government funded ICDS programs which provide free education and nutritional supplements. When parents have the financial resources, they typically send their children to private schools which are reputed to be of higher quality than government ones.

The findings of studies with national samples indicate that the ICDS has played a significant role in improving the survival rate, health and nutritional status, and educational outcomes of children from economically disadvantaged families (NCAER, 2001, NIPPCD, 1992, 2006). However, much research has also been critical of the ICDS. The ICDS provides services through a network of Anganwadis (AWCs) or "courtyards" and in the past, the AWCs were perceived as feeding stations (Rao \& Sharma, 2002); it is only in the past decade that efforts to strengthen the preschool education component have been made. Centers tend to focus on health 
and nutrition over social and cognitive development, lack curriculum resources, have high adult ratios and large group sizes; the childcare workers have low levels of professional training (Rao, 2005; Swaminathan, 1993). Limited attention is allocated to providing high quality curriculum materials, enriching the drab curriculum, improving the quality of teaching and learning, and adding school readiness activities. The preschool component of the ICDS is considered to be one of the weak points of the program (Kaul, 2002). Although the ICDS is in the process of being universalized, it has been pointed out that there is no mechanism to ensure that supplementary nutrition and services actually reach the neediest sector of the population. Furthermore, child care workers are often overworked, and the health, outreach, and education components of the ICDS do not receive adequate attention (World Bank, 1999).

The ICDS program is organized on a project basis. This has helped decentralize the program and reach beneficiaries directly. The centers are less than $30 \mathrm{kms}$. from the Project Office but spread out in different directions. Each project has several sectors under it and these, in turn, are divided into areas with a supervisor in charge of each area.

Each supervisor takes responsibility for about 20 centers and visits them at least once a month and is given bus fare to meet traveling expenses. She ${ }^{1}$ arrives at Centers unannounced and sees whether they are functioning and checks their records and writes a monthly report about the working of each Center which includes her personal observations and recommendations. The main source of continuous monitoring and evaluation is the Mothers' Committee. This consists of eight women- two who are mothers of teenage girls, two who are pregnant, two who are lactating and two who have pre-school age children. The Mothers' Committee oversees the daily activities of the Center and the supervisor meets the Mothers' Committee of the different villages to discuss any problems and transmits information to the Child Development Program 


\section{Officer (CDPO).}

On the $20^{\text {th }}$ day of every month, a meeting of all supervisors for a sector is held and they share their concerns and prepare for their meeting with the CDPO, which is scheduled on the last day of the month. This meeting assesses the working of the centers, solves problems and comes up with a list of issues to be discussed at a meeting of CDPOs at the district headquarters. This meeting takes place on the $2^{\text {nd }}$ and $3^{\text {rd }}$ of every month and is chaired by the Regional Joint Director of the ICDS. The CDPO has a full-day meeting with all supervisors and AWWs on the $5^{\text {th }}$ day of every month to relay information garnered from the previous meeting.

Teacher - Parent Interaction is encouraged. The AWH visits the homes of the younger children daily when she takes children to and from the center. Parents also visit the center at any time convenient to them to discuss their child or any other issue with the AWW. According to the AWWs, some parents come to the center to discuss problems with them but generally once children have adjusted to being in the center, most parent visits are rare.

There are wide variations in ICDS functioning and quality across and within states (Citizens' Initiative for the Rights of Children Under Six, 2006; NIPPCD, 2006). This study was conducted in the state of Andhra Pradesh where the quality of ICDS centers or Anganwadis sampled in a national study was rated as good. Even though there are over 750,000 ICDS centers in India, there have been no published studies which have looked prospectively at the relationship between the quality of centers and child developmental outcomes. It is clear that these ICDS centers, as with others in India, in descending order of priority, have focused on promoting survival, improving nutritional status, and early education. More attention has been directed at determining whether the first of the three objectives has been met.

Against this background, the present study addressed the following research question: 
What is the relationship between the quality of ICDS centers and child development? Based on the extant literature it was predicted that the quality of preschool education would be positively related to child development outcomes.

Method

\section{Research Site}

This study was conducted in two adjacent villages in a district with an overall literacy rate of $66.3 \%$ in the state of Andhra Pradesh in India. The villages had populations of 1072 and 1400, respectively and were located about one hour by road from the state capital. Two ICDS centers under the same Project ${ }^{2}$ were chosen because of their varying distance from the Child Development Project Office. Prominent early childhood education researchers in India have suggested that distance from the Project Office may be an important variable for program quality when staff have relatively low professional training (A. Sharma, personal communication, December 3, 2009). Centers nearer the Office tend to benefit from more inspections, supervisory visits and monitoring and these variables may be associated with program quality.

Every ICDS Center or Anganwadi has one Anganwadi Worker (AWW) and one Anganwadi Helper (AWH) who maintain population records, care for about 10 pregnant and 10 lactating mothers, oversee and support the development of about 50 children ranging in age between six months and six years and maintain detailed records about children's growth and nutritional status.

\section{Participants}

Children, ranging in age from three to six years, are eligible for the preschool component of the ICDS, and there are typically 25 children of this age range enrolled in each center. All children who were regularly receiving the preschool component of the program $(M=49$ months, 
$S D=10$ ) in two ICDS centers were included in the study. There were 18 boys and 17 girls in Center I and 9 boys and 23 girls $^{3}$ in Center Y. This paper reports on their developmental functioning when they had received preschool education for one year and nutritional supplementation for at least one year.

All children were from socially disadvantaged families and met the government criteria for being classified as Below Poverty Line families. The fathers of children in both centers were engaged in similar work (mainly agricultural or construction workers) and the majority of mothers were illiterate.

Participants also included the teachers in Centers I and Y. Their classes were observed and they were interviewed to obtain standard background information and details about the program.

\section{Instruments}

The McCarthy Scales of Children's Abilities (McCarthy, 1972) was used to assess children's level of developmental functioning. Even though this test was developed in the US, it was felt that its use was justified given the universal nature of early child development. Further, there is general agreement on the skills and competencies required for school success and the primary school curricula are similar around the world. The Going Global project (Kagan \& Britto, 2005) worked with six different countries across three continents to develop culturallyrelevant Early Learning and Development Standards (ELDS) and found that the following domains appeared in all countries’ ELDS: Physical Health, Social and Emotional Competence, Language, Communication and Numeracy. With the exception of Physical Health, which was assessed by a physician, the MSCA assessed all these competencies. Some subtests of the MSCA were omitted as they were contextually inappropriate (e.g., solving jigsaw puzzles or 
tapping a tune on a xylophone as children had not been exposed to these previously) and some items were deleted or modified to make them more culturally appropriate (e.g., changing pennies to paisa). Scoring procedures specified in the MSCA manual were followed and the final score was computed by adding the raw scores for each item.

A physician rated each child's health status using Indian norms for height and weight. Ratings were made on a 4-point scale ( 1 = Much below Average (Malnourished); $2=$ Slightly below Average (Slightly Malnourished and Underweight), 3 = Average; 4 = Above Average)

The Tamil Nadu Early Childhood Environment Rating Scale (TECERS) (Isley, 2000) was used to assess preschool program quality.

An interview schedule was developed for teachers. This included questions on teachers' academic background, professional qualifications and work experiences. Teachers were also asked about the delivery and distribution of the supplementary nutrition, adequacy of teaching resources, supervisory visits, communication with parents, their involvement in the community, and the Mothers' committee.

\section{Procedure}

All children had been at the Center for at least one year and received at least one year of the preschool education before they were administered a modified version of the McCarthy Scales of Children's Abilities (MSCA) (McCarthy, 1972, see the Appendix) by a Senior Researcher who was a faculty member in a local teacher training college. These assessments were conducted in the afternoon in the Center after the children had left for the day and were completed over a 1-month period.

The children's health status was assessed by a physician who was unaware which Center the child attended. These assessments, conducted in the local government primary school which 
children from these centers would normally attend, were completed within a 1- month period which coincided with the administration of the MSCA.

The half-day programs were observed by the Senior Researcher for the whole session on three occasions separated by 6-month intervals. These assessments coincided with the beginning, middle and end of the study. The first author also observed two full sessions. The categories of the Preschool Assessment Scale (Rao, Koong, Kwong \& Wong, 2003) which considered structural and process quality and management-related factors were used to provide a qualitative description of program quality. The program was also rated using the PAS and inter-rater reliability between the Senior Researcher and the author was 96\%. However, many items could not be scored as the PAS was not appropriate for the resource-poor early childhood programs observed in the present study. Hence, program quality was formally assessed by the first author at the time when the developmental assessments were conducted using the TECERS (Isley, 2000).

Results

This study examined the relationship between preschool program quality and child development. Preschool quality was assessed through systematic observations of the two preschool centers. Additional information needed to gauge structural quality was obtained from teacher interviews and guidelines for the implementation of the ICDS. Given that this study focuses on quality in a context that may be unfamiliar to many readers of Early Education and Development, qualitative descriptions related to key components that impact on process and structural quality are first provided. Next, scores on the TECERS are provided and finally results from statistical tests applied to examine the relationship between preschool quality and child development are shown. 


\section{Observations of Preschool Quality}

Table 1 provides descriptive information relevant to components of structural, process and management-related quality. This has been done to highlight the commonalities and distinctions between the centers.

Insert Table 1 about here

The centers varied in distance from the Child Development Program Office and this was felt to be an important variable in influencing teacher behavior. The Physical Settings for both centers were similar. They were relatively small, had designated areas to store the scarce materials and no outdoor play equipment. Neither center had a toilet but drinking water was available in both of them.

In terms of Health and Safety, there were lockable gates so there was limited chance of children running onto the road. There was also little equipment which in fact decreased the possibility of having safety hazards.

Basic play materials such as balls, blocks, and crayons were not visible in either of the centers, but there were story books and low-cost, no-cost indigenous materials. There were also resources for teachers to record children's progress and to provide parent education.

Teacher qualifications are a key component of structural quality and information about teacher characteristics which was obtained from interviews and observations is also presented in Table 1. Both AWWs met the minimum qualifications for the job and appeared committed to their roles. However, the AWW in Center I seemed more motivated and achievement oriented than the one in Center Y. She completed her degree a few years earlier while the AWW in 
Center Y did not pursue further education. ICDS centers are given a grade from 1 to 3 at the end of each year with Grade 1 being the highest score obtainable. Center I has the distinction of being a Grade 1 center.

The daily routine in the two centers was very similar and any differences in child outcomes between children in the two centers can not be attributed to differences in this. The following sequence of events was observed over 12 visits to the centers. The AWH fetched younger children from their homes. On any typical day, although the AWW and AWH opened the Center by about 9.00 a.m., children only started drifting in by about 10.30 a.m., except in a few cases when both parents go out to work and had the child dropped at the Center soon after it opened. Older children know that the supplementary nutrition is given at noon hence they did not come earlier.

By about 10.30 a.m., when most of the children have assembled and the AWH is there to supervise them, the AWW began her record work. She took attendance, checked for health problems and measured out the food. By about 11.15 a.m., she led an interactive session with the children and this typically lasted for 45 minutes. The AWW in Center I used more developmentally appropriate instructional strategies during the interactive session than the one in Center Y. During this session, the AWW and the AWH squatted on the floor at the children's eye level. They sang songs, recited rhymes and poems which were often related to counting, alphabets or proper behavior. Both of them addressed all the children by name and had eye contact with the children when they spoke. The children were active during this session. On the other hand, in Center Y the AWW used instructional strategies which were less engaging of the children.

At noon, the AWW and AWH became busy with the routine of distributing the nutrition 
supplement which is a specially developed high protein calorie-rich powder which children like. After children ate the supplement, they got ready to go home. For the next half an hour, the AWW updated all the records for the day, put away any material used by the children and cleaned up the Center ready for the next day. Although the teachers maintained a daily diary, there was no stringent evaluation of the preschool activities as in the case of health, nutrition and immunization.

\section{TECERS}

Center I and Y received scores of 78 and 51, respectively on the TECERS. As shown in Table 2, the two centers did not differ on structural variables (infrastructure, personal care routines and physical learning aids) but there were differences on sub-scales related to process quality. It should be noted that even Center I would be considered of poor quality by EuroAmerican standards.

Insert Table 2 about here

\section{Child Outcomes across Centers}

As shown in Table 3, there were significant intercorrelations between age, weight, and height; and physician's ratings of health and weight and height. There were also significant intercorrelations between age, perception, speech, memory and numeracy.

A MANOVA with Sex (2) and Site (2) as independent variables and the physician's rating of health (nutritional and developmental status), $z$ Weight and $z$ Height as dependent variables were conducted. For both the analyses, none of the main effects or interactions were significant $(\mathrm{p}>.05)$. 
Insert Tables 3, 4 and 5 about here

The raw scores for perception, motor skills, memory, speech and numeracy were summed to get a Developmental Index. A hierarchical regression with the Developmental Index as the dependent variable and Age, Sex and Site as predictors was conducted. As shown in Table 4, three variables contributed significantly to prediction and accounted for $71 \%$ of the variance. Age was entered first and contributed to $35 \%$ of the variance while Sex and Site contributed another $5 \%$ and $31 \%$ of the variance, respectively.

\section{Discussion}

This study examined the relationship between preschool quality and child development in rural South India. Children who attended two different ICDS centers under the same Project Office were compared on developmental functioning and the quality of the centers was assessed.

\section{Preschool Quality}

While government funded inputs were the same for both centers, and there were no differences in structural quality between the centers one of them had better process quality than the other. Several factors seemed to contribute to the difference in quality. The higher quality center was closer to the Project Office and received more informal supervision and monitoring than the other. As is the case in most developing countries, the AWW have relatively low levels of academic and professional training and this exposure and informal interactions with supervisors and the CDPO may have positively influenced the AWW in this center as she went on to pursue a degree. Compared to the AWW in Center Y, the one in Center I seemed more committed to facilitating children's development. She appeared to engage children in more 
activities while children in the other center spent more time just "sitting around". The difference in engagement of the children in the two centers was clearly discernable. Another factor which may have contributed to differences in process quality was the differences between the Mothers' Committees in the villages served by the two ICDS centers. For example, the Mothers' Committee was more involved in the day-to-day matters of the ICDS center in Center I than in Center Y. They had monthly meetings to share their concerns about the program and these were transmitted to the AWW. For example, they wanted the AWW to teach the English alphabet and rhymes to children in the center.

\section{Child Outcomes across Centers}

We selected all children in the center and it was not possible to control for the possibility that children who lived closer to one center were from more advantaged families. However, all families were Below the Poverty Line according to government criteria. Further, we obtained information about father's occupation (a proxy for income) and found that fathers of children in both centers were engaged in similar work.

Children in the higher quality center had better perceptual, memory, verbal and numerical skills than the one with lower quality, indicating that quality is related to child outcome measures. In fact, $31 \%$ of the variance in developmental functioning was explained by site, a proxy for Preschool Quality. Unexpectedly, gender significantly contributed to prediction of developmental functioning with boys attaining higher scores than girls. This may be because of the strong son preference and parents may give more attention to sons than daughters and teachers may inadvertently do so as well.

On account of the relatively few educational resources and the large group size, teacherinitiated interactions were directed at the whole group and typically involved talking, chanting, 
counting and singing. Children in the higher quality preschool had better literacy skills which are more important for early school achievement. Even in these low resource environments, simply talking to children and asking them questions has benefits for their development.

Lessons can be learned from less technologically advanced societies about the implementation of pedagogically effective, low-cost interventions in low resource environments which prepare children for the types of primary schools they will enter.

The results from this small-scale study are in keeping with other studies conducted in India, Bangladesh, the US and the UK (Aboud, 2004, MSSRF, 2000, NICHD ECCRN, 2005; Sylva et al. 2006), which have shown a relationship between the quality of care received and child outcomes. It is important to reiterate that the quality of these preschools would be considered extremely low if we apply standards for preschool quality adopted in the western world. This suggests that the minimal quality provided by programs that include some teacherdirected activities, makes a positive difference to child development and school readiness. However, at the same time, research has highlighted the importance of high quality preschool education of child development. Children will not benefit from preschool provision if the quality of care and education they receive is poorer than what they would receive if they did not attend.

The findings from this exploratory study have implications for the preschool component of the ICDS. The ICDS has led to lower infant and child mortality rates and better nutritional status (NCAER, 2001; NIPCCD, 1992, 2006; Rao, 2006). The major weakness of the ICDS is the lack of the implementation of the preschool education component. The ICDS authorities are aware of this and provide training, materials and guidelines for the preschool education component. A system of assessing children's holistic development at regular intervals must take place if we are to see more attention being given to cognitive development. Given the amount of 
time required for monitoring and recording health status and the lack of manpower, this may place much more burden on the already overworked AWW, AWH or the system itself. However, as long as all aspects of a child's growth and development are not taken into consideration and made to count as a measure of the effectiveness of the program, the ICDS program will not fulfill its potential.

While national level studies are more influential in affecting policy, systematically conducted small scale studies can provide additional information on ways to enhance quality. For example, while previous research has documented urban and rural differences in the functioning of ICDS centers, the amount of support provided is important for maintaining and enhancing preschool quality. In rural areas, location and amount of supervision provided are confounded as supervisory staff tend to neglect hard to reach centers. Hence, more "inspection" visits can be scheduled to remote rural and tribal areas where mothers tend to have lower levels of education.

The findings from this small-scale exploratory study need to be replicated with larger nationally representative samples. Further research should be concerned with the development of evidence-based theoretical models which will allow us to better understand and predict child development outcomes in at-risk populations in the developing world.

\section{Conclusions}

The quality of education provided by these two preschools would be considered very poor if assessed using definitions of preschool quality developed in the west. However, when mothers are illiterate and families are very poor, the food supplementation and minimum input provided by teacher-directed stimulation promotes child development. Preschool effectiveness should be evaluated by contextually appropriate outcomes for children (Myers, 2006). 
Consistent with larger-scale national studies conducted in India (NCAER, 2001; NIPPCD 1992, 2006), we found that the ICDS has benefits for children.

There are several limitations of this study including the small sample size, the fact that only two ICDS centers and the lack of a control group. Further, since the study was not longitudinal the influence of pre-intervention differences between the samples can not be ruled out. However, this is the first study in India to assess the quality of two ICDS centers concurrently and longitudinally and examine the relationship between quality and child development. Further, the findings are important in the broader international context of early childhood development and education. Indeed, the majority of the world's children live in the developing world and by doing research in different contexts, we broaden the range of variables studied thereby enabling us to assess the generalizability of research findings from other countries. For example, preschools with the (relatively poor) quality observed in this study would not be seen in the developed world. Yet the results indicate that even in this impoverished context, preschool quality is related to child development. 


\section{References}

Aboud, F.E. (2004). Evaluation of an early childhood preschool program in rural Bangladesh. Early Childhood Research Quarterly, 21, 46 - 60.

Association for Childhood Education International (ACEI). (2006). ACEI Global Guidelines Assessment. Retrieved July 9, 2009, from http://www.acei.org/wguideshp.htm

Citizens' Initiative for the Rights of Children Under Six (2006). Focus on Children Under Six. New Delhi, India: Mensa Computers. Retrieved March 8, 2007, from http://www.righttofoodindia.org/data/rtf06focusreportabridged.pdf

Cost, Quality and Child Outcomes Study Team (1995). Cost, Quality and Child Outcomes in Child Care Centers. Executive Summary. Denver, CO: University of Colorado.

Dahlberg, G., Moss, P., \& Pence, A. (1999). Beyond Quality in Early Childhood Education and Care: Postmodern perspectives. London: Falmer.

Engle, P.L., Black, M.M., Behrman, J.R., de Mello, M. C., Gertler, P. J., Kapiriri, L., and the International Child Development Steering Group (2007). Child development in developing countries 3: Strategies to avoid the loss of developmental potential in more than 200 million children in the developing world. The Lancet, 369 (9557), 229-242.

Government of India (2007). Integrated Child Development Services (ICDS) Scheme. New Delhi, India: Department of Women and Child Development. Retrieved July 8, 2009, http://wcd.nic.in/

Grantham-McGregor, S., Cheung Y.B., Cueto, S., Glewwe, P., Richter, L. \& Strupp, M. (2007). Child development in developing countries 1: Developmental potential in the first 5 years for children in developing countries. The Lancet, 369(9555), 60-70.

Harms, T., \& Clifford, M. (1980). Early Childhood Environment Rating Scale (ECERS). New 
York: Teachers College Press.

Isley, B.J. (2000). Tamil Nadu Early Childhood Environment Rating Scale (TECERS). Chennai, India: M.S. Swaminathan Research Foundation.

Lamb, M. E. (1998). Nonparental child care: Context, quality, correlates and consequences. In I. E. Sigel \& A. Renninger (Eds.), Handbook of Child Psychology (Vol. 4, pp. 73-133). New York: Wiley.

Kagan, S.L. \& Britto, P.R. (2005). Going global with indicators of child development. UNICEF Final Report. New York: UNICEF.

Kaul, V. (2002). Early Childhood Care and Education. In R. Govinda (Ed.) India Education Report. New Delhi, India: Oxford University Press.

M.S. Swaminathan Research Foundation. (2000). Quality Matters: Understanding the Relationship between Early Childhood Education and Learning Competencies of Children. Chennai, India: M.S. Swaminathan Research Foundation.

McCarthy, D. (1972). McCarthy Scales of Children's Abilities. TX: The Psychological Corporation.

Montie, J.E., Xiang, Z., Schweinhart, L. J. (2006). Preschool experience in 10 countries: Cognitive and language performance at age 7. Early Childhood Research Quarterly, 21, $313-331$

Moore, A.C., Akhter, S., \& Aboud, F. E. (2008). Evaluating an improved quality preschool program in rural Bangladesh. International Journal of Educational Development, 28, 118-131.

Myers, R.G. (2006). Quality Issues related to Early Childhood Learning. In International Institute of Educational Planning Newsletter, 24 (1). Paris: IIEP/UNESCO. Retrieved on 
September 19, 2006, from http://www.unesco.org/iiep/eng/newsletter/2006/jane06.pdf

National Council of Applied Economic Research. (2001). Concurrent Evaluation of Integrated Child Development Services: National Report. New Delhi: Author.

NICHD Early Child Care Research Network (2005). Child care and child development: Results from the NICHD study of early child care and youth development. New York: Guildford Press.

National Institute of Public Cooperation and Child Development (NIPCCD). (1992). National Evaluation of Integrated Child Development Services. New Delhi: Author.

National Institute of Public Cooperation and Child Development (NIPCCD). (2006). Three decades of ICDS: An appraisal. New Delhi: Author. Retrieved on April 9, 2007, from http://wcd.nic.in/

Peisner-Feinberg, E. S., Burchinal, M. R., Clifford, R. M., Culkin, M. L., Howes, C., Kagan, S. L., \& Yazejian, N. (2001). The relation of preschool child-care quality to children's cognitive and social developmental trajectories through second grade. Child Development, $72,1534-1553$.

Prochner, L., 2002. Preschool and playway in India. Childhood: A Global Journal of Child Research, 9, 435-453.

Rao, N. (2005). Children's Rights to Survival, Development and Early Learning in India: The Critical Role of the Integrated Child Development Services Program. International Journal of Early Childhood, 37 (3), 15-31.

Rao, N. (2007). Strong Foundations for Gender Equality in Early Childhood. Advocacy Brief. Bangkok, Thailand: UNESCO Bangkok.

Rao, N., Koong, M., Kwong, M. \& Wong, M. (2003). Predictors of Preschool Process Quality in 
a Chinese Context. Early Childhood Research Quarterly, 18, 331-350.

Rao, N. \& Pearson, V. (2008). Transforming Early Childhood Care and Education in the Insular South East Asia and Mekong Sub-Regions: Implications of the Global Monitoring Report 2007. Bangkok, Thailand: UNESCO.

Rao, N. \& Sharma, A. (2002). Early Childhood Services in India: Challenges and prospects for their development. In L.K.S. Chan \& E. Mellor (Eds.) International Developments in Early Childhood Services (pp. 97-117). New York: Peter Lang.

Save the Children (2003). What's the Difference? An ECD Impact Study from Nepal. Nepal:

Save the Children. Retrieved September 19, 2006, from http://www.unicef.org/media/index_29686.html

Sylva, K., Siraj-Blatchford, I., \&Taggart, B. (2003). Assessing quality in the early years: Early Childhood Environment Rating Scale - Extension (ECERS-E): Four curricular subscales. Stoke-on-Trent: Trentham Books

Sylva, K., Siraj-Blatchford, I., Taggart, B., Sammons, P., Melhuish, E., Elliot, K., \& Totsika, V. (2006). Capturing quality in early childhood through environmental rating scales. Early Childhood Research Quarterly, 21(1), 76-92.

Swaminathan, M. (1993). Current Issues in Early Childhood Care and Education. In T.S. Saraswathi \& B. Kaur (Eds.). Human Development and Family Studies in India: An Agenda for research and policy (pp. 221 - 232). New Delhi: Sage Publications.

Tobin, J. (2005). Quality in early childhood education: An Anthropologist's perspective. Early Education and Development, 16, $421-434$.

Tobin, J., Davidson, D., \& Wu, D. (1987). Class-size and student-teacher ratios in the Japanese preschool. Comparative Education Review, 31, 533-549 
UNICEF. (2008). The child care transition, Innocenti Report Card 8, Florence, Italy: UNICEF Innocenti Research Centre.

UNESCO. (2007). EFA Global Monitoring Report 2007. Strong Foundations: Early Childhood Care and Education. Paris: Author.

Vandell, D.L., \& Wolfe, B. (2000). Child care quality: Does it matter or does it need to be improved? (special report no. 78.) University of Wisconsin-Madison: Institute of Research on Poverty.

Woodhead, M. (1999). Towards a Global Paradigm for Research into Early Childhood Education. European Early Childhood Education Research Journal, 7, 5-22.

World Bank. (1999). Health Care in India: Learning from Experience. Precis No. 187. World Bank Operations Evaluation Department. Washington D.C.: Author.

Zaveri, S. (1993). India Village Preschool Study. Report on an Experimental Phase (January 1991 - October 1993). Report prepared for the Aga Khan Foundation (AKF). Geneva, Aga Khan Foundation. 
Table 1

Key Components of Preschool Quality Centers I and Y

\begin{tabular}{|c|c|c|}
\hline & Center I & Center Y \\
\hline \multicolumn{3}{|c|}{ Factors that Influence Process Quality } \\
\hline Location & $\begin{array}{l}\text { Next to the Child Development } \\
\text { Program Office }\end{array}$ & $\begin{array}{l}\text { A few miles from the Child } \\
\text { Development Program Office }\end{array}$ \\
\hline \multirow[t]{2}{*}{ Physical Setting } & $\begin{array}{l}\text { Center I has a room }(2.5 \mathrm{~m} \mathrm{X} 3 \mathrm{~m}) \\
\text { and an adjoining verandah about the } \\
\text { same size. This room contains a } \\
\text { raised platform to store materials for } \\
\text { the Supplementary Nutritional } \\
\text { Program, weighing scales, toys, } \\
\text { books, records of current program } \\
\text { beneficiaries, children's development } \\
\text { registers and wall posters. The } \\
\text { children sit, play and eat in the } \\
\text { verandah and there is a black board. } \\
\text { There is an open area of about } 90 \mathrm{~m}^{2} \\
\text { all around the building where the } \\
\text { children play, weather permitting. }\end{array}$ & $\begin{array}{l}\text { Center Y consists of a large room ( } 3 \\
\mathrm{~m} \text { X by } 4.5 \mathrm{~m}) \text {, a smaller storage } \\
\text { room }(2.5 \mathrm{~m} \mathrm{X} 2.5 \mathrm{~m} \text { ) and an open } \\
\text { verandah which opens directly on the } \\
\text { street. The large room is the main } \\
\text { activity area. There are wall displays } \\
\text { and a blackboard on which notices } \\
\text { about the monthly meetings are } \\
\text { written. In one corner of the room is } \\
\text { a model of a typical village with } \\
\text { replicas of a bank and a post office } \\
\text { which are used as instructional aids. } \\
\text { This room is connected to the smaller } \\
\text { room where food is stored on a raised } \\
\text { platform. Toys, floor mats and } \\
\text { several chairs were neatly stacked. }\end{array}$ \\
\hline & \multicolumn{2}{|c|}{ There is no toilet, but drinking water is available. } \\
\hline $\begin{array}{l}\text { Health and } \\
\text { Safety }\end{array}$ & \multicolumn{2}{|c|}{$\begin{array}{l}\text { There is no outdoor playground equipment and few resources for children so } \\
\text { there is no concern about the safety hazards due to faulty items. The windows } \\
\text { are barred and in both centers all rooms are at ground level. }\end{array}$} \\
\hline $\begin{array}{l}\text { Materials } \\
\text { available in the } \\
\text { Centers }\end{array}$ & \multicolumn{2}{|c|}{$\begin{array}{l}\text { Similar materials were available in both centers. Both centers have weighing } \\
\text { scales and measuring tapes to assess children's growth and nutrition status. } \\
\text { Both of them had blackboards on which notices and slogans and posters } \\
\text { supplied by the government were displayed. These posters were used by } \\
\text { teachers to inform parents about good parenting practices. Literature relating } \\
\text { to: nutrition, child care, immunization, care to be taken by pregnant and } \\
\text { lactating women, the empowerment of women and the need for education for } \\
\text { youth welfare could be seen at both centers. Basic play materials such as } \\
\text { balls, blocks, and crayons were not visible in any of the centers, but there } \\
\text { were story books and low-cost, no-cost indigenous materials. }\end{array}$} \\
\hline $\begin{array}{l}\text { Staff } \\
\text { Qualifications }\end{array}$ & \multicolumn{2}{|c|}{$\begin{array}{l}\text { To be selected as an AWW, a woman has to pass Class } 7 \text { and must need the } \\
\text { financial support provided by the job. The AWWs in both the centers were } \\
\text { recruited through this process and both of them received residential pre- } \\
\text { service training and attended a refresher course } 5 \text { years after their initial } \\
\text { training. They also attend professional development courses, which are held } \\
\text { at the Project Office, at regular intervals. } \\
\text { Both AWWs appeared sincere and committed, and completed their assigned } \\
\text { duties both within and outside the Center. Their responsibilities in the }\end{array}$} \\
\hline
\end{tabular}




\begin{tabular}{|c|c|c|}
\hline & \multicolumn{2}{|c|}{$\begin{array}{l}\text { community include maintaining census records of the area, educating teenage } \\
\text { girls, ensuring immunizations for mothers and children, and conducting AIDS } \\
\text { awareness programs. } \\
\text { The AWH does not need any formal educational qualification prior to } \\
\text { recruitment. }\end{array}$} \\
\hline $\begin{array}{l}\text { Teacher } \\
\text { Characteristics }\end{array}$ & $\begin{array}{l}\text { The AWW in Center I was motivated } \\
\text { and achievement oriented. She } \\
\text { completed her degree a few years } \\
\text { earlier. } \\
\text { The AWW won an award and her } \\
\text { center was rated as a Grade } 1 \text { center. }\end{array}$ & $\begin{array}{l}\text { The AWW did not pursue further } \\
\text { education. }\end{array}$ \\
\hline $\begin{array}{l}\text { Management } \\
\text { and Evaluation }\end{array}$ & \multicolumn{2}{|c|}{$\begin{array}{l}\text { Each supervisor takes responsibility for about } 20 \text { centers and visits them at } \\
\text { least once a month. }\end{array}$} \\
\hline $\begin{array}{l}\text { Teacher - Parent } \\
\text { Interaction }\end{array}$ & \multicolumn{2}{|c|}{$\begin{array}{l}\text { The AWH visits the homes of the younger children daily when she takes } \\
\text { children to and from the center. Parents also visit the center at any time } \\
\text { convenient to them to discuss their child or any other issue with the AWW. }\end{array}$} \\
\hline
\end{tabular}


Table 2

Scores on the TECERS for Centers I and Y

$\begin{array}{lcc} & \text { Center } & \text { Center } \\ & \text { I } & \text { Y } \\ \text { Infrastructure } & 13 & 12 \\ \text { Personal Care Routines } & 6 & 6 \\ \text { Physical Learning Aids } & 8 & 8 \\ \text { Language and Reasoning Activities } & 9 & 7 \\ \text { Fine \& Gross Motor Activities } & 10 & 7 \\ \text { Creative Activities } & 9 & 6 \\ \text { Social Development } & 16 & 12 \\ \text { Total TECERS } & 71 & 58\end{array}$




\section{Table 3}

Intercorrelations among developmental variables

\begin{tabular}{|c|c|c|c|c|c|c|c|c|c|c|}
\hline & & & & & Motor & & & & & \\
\hline Age & & $0.74 * *$ & $0.69 * *$ & -0.17 & 0.18 & $0.67 * *$ & $0.32 * *$ & $0.42 * *$ & $0.72 * *$ & $0.60 * *$ \\
\hline Height & & & & $0.32 * *$ & $0.29 *$ & $0.57 * *$ & 0.19 & $0.41 * *$ & $0.58^{* *}$ & $0.51 * *$ \\
\hline Physical & & & & & 0.14 & 0.10 & 0.01 & 0.08 & -0.12 & 0.70 \\
\hline Motor Skills & & & & & & $0.41 * *$ & $0.53 * *$ & $0.49 * *$ & $0.26^{*}$ & $0.63 * *$ \\
\hline Memory & & & & & & & & & $0.60 * *$ & $0.83 * *$ \\
\hline
\end{tabular}

$* \mathrm{p}<.05, * * \mathrm{p}<.01$ 


\section{Table 4}

Means and SDs for Developmental Variables across Site and Sex

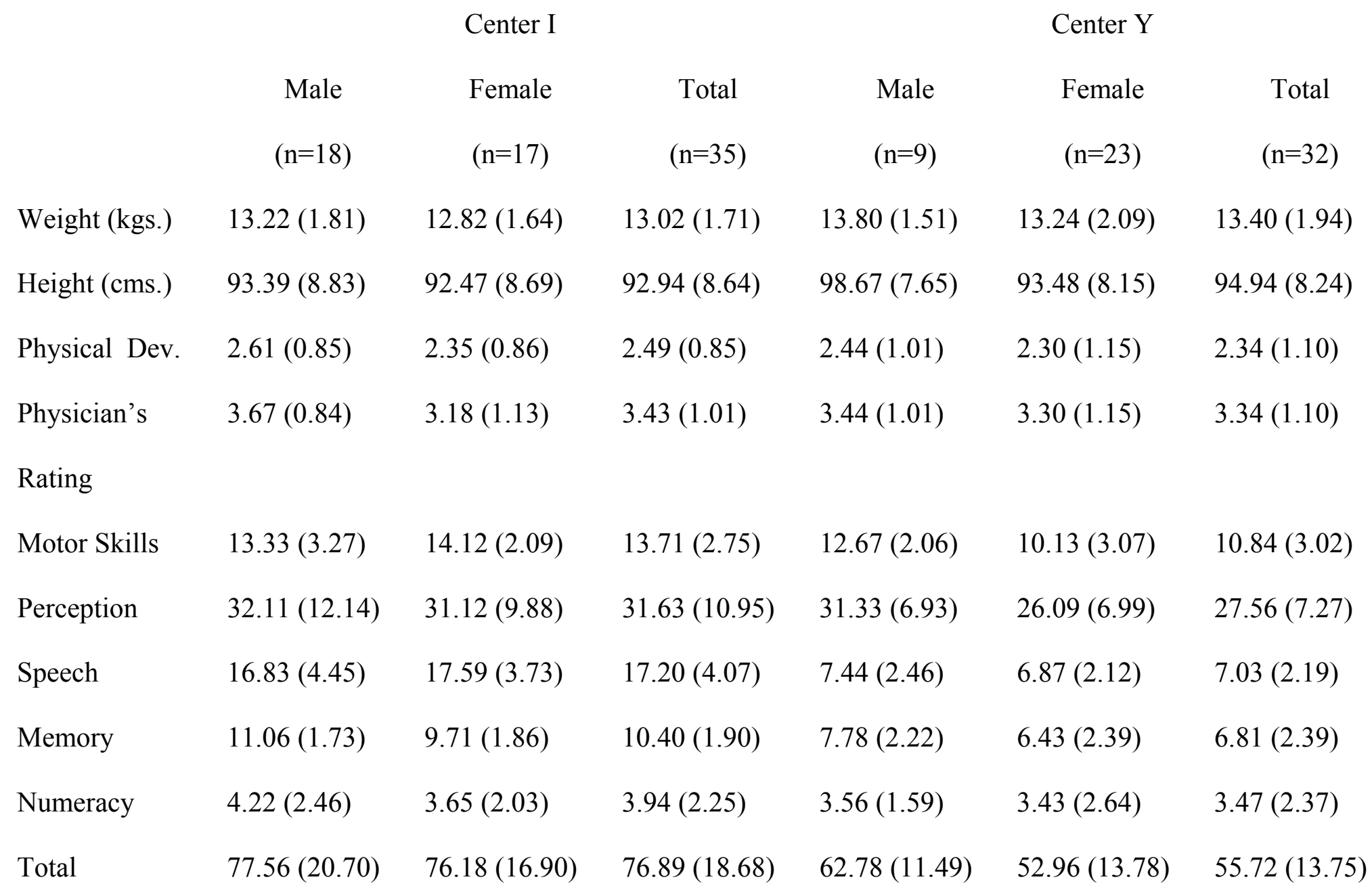


Table 5

Summary of Hierarchical Regression for Prediction of Developmental Index

\begin{tabular}{|c|c|c|c|c|c|c|c|c|c|}
\hline Predictors & B & SE B & $\beta$ & df & $t$ & $F$ & $R$ & Adjusted & $F$ Change \\
\hline & & & & & & & \multicolumn{3}{|c|}{$R^{2}$} \\
\hline Step 1 & 9.84 & 9.65 & & 64 & 1.02 & $36.29 * *$ & 0.60 & 0.35 & 1 \\
\hline Age & 1.16 & 0.19 & 0.60 & & $6.02 * *$ & & & & \\
\hline Step 2 & 25.14 & 11.21 & & 63 & $2.24 *$ & $22.51 * *$ & 0.64 & 0.40 & 1 \\
\hline Age & 1.15 & 0.19 & 0.59 & & $6.19 * *$ & & & & \\
\hline Sex & -9.25 & 3.79 & -0.23 & & $-2.44^{*}$ & & & & \\
\hline Step 3 & 44.50 & 8.05 & & 62 & $5.53 * *$ & $55.65 * *$ & 0.85 & 0.71 & 1 \\
\hline Age & 1.25 & 0.13 & 0.65 & & $9.76 * *$ & & & & \\
\hline Sex & -3.77 & 2.69 & -0.10 & & -1.40 & & & & \\
\hline Site & -22.47 & 2.65 & -0.58 & & $-8.49 * *$ & & & & \\
\hline
\end{tabular}




\section{Appendix}

\section{Developmental Test for Children}

$\begin{array}{ll}\text { Motor skills } & \text { 1. Leg co-ordination } \\ & \text { 2. Arm co-ordination } \\ & \text { 3. Imitative action } \\ \text { Perceptual } & \text { 4. Block Building } \\ \text { Performance } & \text { 5. Conceptual grouping } \\ & \text { 6.Tapping sequence } \\ \text { 7. Draw a design } \\ \text { 8. Draw a child } \\ \text { 9. Picture Memory } \\ \text { 10. Numerical } \\ \text { 11. Word knowledge } \\ \text { 12. Verbal fluency } \\ \text { 13. Number questions } \\ \text { 14. Counting and Sorting }\end{array}$




\section{Footnotes}

${ }^{1}$ There are no male ICDS supervisors or child care workers.

${ }^{2}$ The ICDS is organised under Projects and at the time of the study, the Project Office covered 125 centers.

${ }^{3}$ ICDS centers have in some years been requested to take more girls because of concern over deprivation of the girl child and the implementation of the Girl Child Protection Scheme. 